\title{
We are entering a new era of migration
}

Written by: Jean-Christophe Dumont, Head of International Migration Division, Directorate for Employment, Labour and Social Affairs, OECD

Last update: 29 September 2015

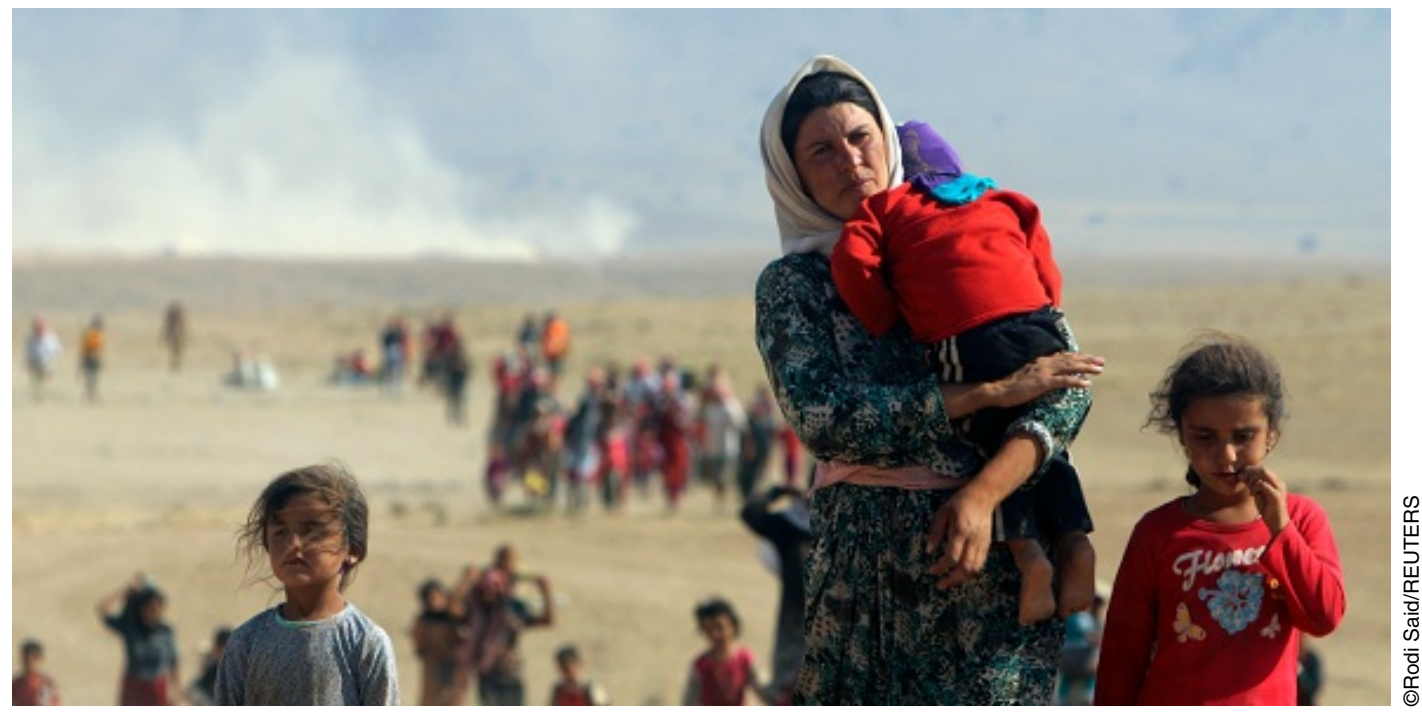

We are entering a new era of migration

Even before the refugee crisis hit European countries, migration was at the top of the international policy agenda. All sides of such a sensitive debate have made appeals to people's emotions, but there must also be room for facts to inform policy discussions.

With approximately 232 million international migrants in a world of 7 billion inhabitants, migration remains small in proportion to the overall population. Nevertheless, this still accounts for a large proportion of people in some countries-on average about $13 \%$ of the population in OECD countries is foreignborn, albeit with a wide range of different proportions from one country to the next. Recent trends indicate that an increase in this ratio is likely to continue for some time.

Most world leaders and high-level policymakers gathering in New York for the UN Sustainable Development Summit (25-27 September 2015) increasingly recognise the potential of migration as a force for social and economic change. However, not 
everyone is convinced. Even with the refugees in Europe, there is a sense of public opinion being torn between sympathy for the personal stories of hardship and terror, and concerns about how asylum-seekers can be accommodated. The more positive picture, of migration as a source of shared prosperity and inclusive growth, should be highlighted.

\section{Here to stay}

A sensible starting point is to recognise that migration has always been part of human history and is here to stay. After a slowdown due to the great recession in 2007-08, the increase in migration flows to the OECD and to the rest of the world resumed. The recently published 2015 edition of International Migration Outlookrecords about 4 million new permanent immigrants to OECD countries in 2014 (see www.oecd.org/migration/imo). Moreover, there are almost as many temporary migrants, such as students. Asylum requests have reached an historical high of 800,000 .

Overall, between 2000-2001 and 2010-2011 the total number of foreign-born people in the OECD increased by $40 \%$. Today there are almost 120 million migrants worldwide, over half of whom are hosted in OECD countries. A closer look at these trends shows several patterns which policymakers need to take into account.

First, migrants tend more to be highly skilled than people who remain in their country of birth. Over the past decade, the number of tertiary educated immigrants aged 15 and older living in the OECD increased by $70 \%$ to 31 million, compared with a rise of just $10 \%$ among the low educated. This growth was largely driven by migrants coming from Asia.

In fact, the emigration rates of the highly educated are higher than overall total emigration rates in most countries. Some $10 \%$ of all highly educated people born in Africa were living in an OECD country in 2010/11, the highest incidence of brain drain in the world. Latin America and the Caribbean are close behind, with $8 \%$.

The focus of policymakers on highly skilled migration is likely to continue, and may even increase in the coming decades. But lesser skilled migration will not disappear because of the persistent and unmet demand in OECD countries for workers in sectors such as agriculture, construction and domestic services.

Second, intra-regional migration is increasing as people move around more and more within their home continents. The recent waves of enlargement of the EU in 2004, 2007 and 2013 help explain this trend: the OECD estimates that about 18 million people have moved within the region, which is about $50 \%$ more than in 2004. Similar trends are observed in other parts of the world where regional agreements facilitate cross-border mobility, such as in Latin America in the context of Mercosur, in Asia with ASEAN and, to a lesser extent, in Africa.

Third is the obvious but still painful fact that recent migration trends, notably to Europe, have been fuelled by the geopolitical turmoil and conflict in the 
Mediterranean area, Africa and the Middle East, with an upsurge in the flow of refugees who are in need of protection. As OECD Secretary-General Angel Gurría underlines in a statement in support of efforts to address this challenge, leaders must stand before history in dealing with this humanitarian tragedy. Migrants from Syria and Eritrea made up about half of the illegal entries recorded in the EU in 2014. The other half included people from Afghanistan, Iraq and Ukraine, as well as relatively large numbers of people from peaceful and growing economies. This diversity is a new reality that policymakers must face up to in the years ahead.

Policymakers will have to consider how migration fits with other demographic changes, too. There is no automatic link between demographic and migration trends, and the role migration plays in meeting future labour market needs in destination countries will depend on the ability to match the supply and demand for skills in origin and destination countries. Nevertheless, Europe and the rest of the OECD are ageing rapidly, but Africa and several countries in Asia have an overabundance of young people. By about 2035 the gap between the dependency ratios-which is the size of the working age population relative to the population aged over 65-in Europe and Africa will be at its widest, with the former being five times higher than the latter (44\% compared with $9 \%$ ). This gap between the rest of Asia and Japan has already peaked, and will do so between the US and Latin America by around 2025.

\section{An economic boon}

There is a growing realisation that migration has the potential not only to play a positive role in the economic and social development of destination countries, but in origin countries, too, as migrants return with skills and money. The fact that under the Sustainable Development Goals, policymakers now view international migration as "a multi-dimensional reality of major relevance for the development of countries of origin, transit and destination", opens the door for real progress in addressing key migration challenges and fostering international co-operation in this area. This builds on previous statements, for instance in the context of the Global Forum on Migration and Development since its launch in 2006, and of the UN High-Level Dialogue on International Migration and Development under way since October 2013.

What will this entail? For a start, it will reconcile positions taken in international fora with the growing hostility against migration that is increasingly visible in many major destination countries. One approach might be to spell out the potential benefits of migration more clearly, but also more honestly. Migration can be beneficial overall, but some groups, such as the unskilled, may suffer if many unskilled migrants enter a country. A balance must be struck between the need to offer opportunities to the local workforce and to allow for labour migration to fill structural skill shortages, for instance. Another crucial part is to promote policies which improve opportunities in countries of origin, including by 
harnessing the skills of returnee migrants. Above all, countries need strategies to integrate migrants into their social and economic life, preventing seclusion and alienation.

The last point is crucial because integration is one of the cornerstones of the positive migration story being emphasised in New York. The difference between "us" and "them" is not about background-after all, almost everyone is the fruit of migration, and often dating not that far back-but rather that "we" are the integrated ones, whereas "they" are not. All the more reason why integration is so vitally important for the public acceptance of future legal flows. Furthermore, only those who are successful in the destination country will have new skills and sufficient financial resources to share with their communities of origin.

But there is a long way to go. A recent OECD report on the integration of immigrants and their children has shown that "where you or your parents were born still casts a long shadow over your life chances". Even more remarkable is the fact that, in a context of global competition for talent, this statement also holds true for tertiary educated migrants; indeed, half of this group in the OECD area is either inactive, unemployed or in a job for which they are overqualified.

\section{Moving forward}

International migration is not cost-free in the short term, nor even in the medium term, and will remain challenging for both origin and destination countries. However, with the right approach policymakers can outweigh the costs by harnessing the benefits of migration and opening up new opportunities at national, regional and international levels. Whether we step into this new migration era with the best foot forward will depend largely on leadership. Leadership is needed, not only to develop robust migration policies (though more is known about what policies work in helping migrants than most people realise) and to communicate them clearly in a balanced, fact-based dialogue. It is time to shape a global consensus on the positive impact that migration has on our economies and societies, and on people's lives everywhere.

@OOECD Observer No 303, September 2015

\section{References}

Arslan, C. et al (2014), "A new profile of migrants in the aftermath of the recent economic crisis", OECD Social, Employment and Migration Working Papers, No 160, OECD Publishing oecd-ilibrary.org/social-issues-migration-health/a-newprofile-of-migrants-in-the-aftermath-of-the-recent-economiccrisis_5jxt2t3nnjr5-en

OECD (2015), Connecting with Emigrants: A Global Profile of Diasporas, OECD Publishing http://www.oecd.org/migration/diasporas.htm

For more on regional migration, visit the regional observatory systems set up with partner organisations for Asia https://www.oecd.org/migration/buildinghuman-capital.pdf 
For Latin America www.oecd.org/migration/sicremi.htm 